\title{
VALUES, TECTNOLOGY AND WORK
}

by

Enid Mumford

Reader in Organisational Sociology

Manchester Business School, England.

\section{Introduction}

This paper describes some of the results of research carried out by the author into the design of a number of large scale computer systems affecting white collar employees. The objective of the research was to establish the extent to which the values of computer technologists, top management and user management and clerks influenced the design objectives that were set for these systems and their human consequences.

Six systems were studied: three of these were large government applications, two were in industry and one in a large international bank.

\section{Eramework of analysis}

Any useful and meaningful interpretation of research data requires a framework for analysis which will assist the description and understanding of the research situations. The analytical framework for this paper has been dexived from the work of Talcott Parsons (1). Parsons provides a framework for classifying action, or goal directed behaviour, in texms of the meaning of that action for the people concerned and its consequences for a particular system. The four components of this model are 'goal attaimment', 'adaptation', 'integration' and 'pattern maintenance'. Actions directed at the attainment of goals will directly reflect the values of the social system in which the action takes place. Adaptive behaviour facilitates the attainment of these goals, while integrative acts ensure that a system subjected to change either maintains its equilibrium or reverts to a state of equilibrium once the change is completed. Pattern maintenance acts are those that he $1 p$ sustain the new pattern of behaviour once it is adopted ${ }^{(2)}$.

\section{Goal attaiment}

Goal attainment covers the setting of goals and the actions that contribute 
directly to the realisation of these goals. If goals have been defined in technical terms, then goal attainment will be the processes of technical systems design. Goal attainment usually involves cooperation, conflict and the use of powex. It can also involve the manipulation of people's perception, so that the new is seen as prefexable to the old. (3)

\section{Adaptation}

Adaptation is said to have taken place when a group or unit is able to interact successfully with its environment, in the sense that it gets from this environment the inputs which enable it to meet its needs, and is able to return to the enviroment those things of which it wants to dispose. Adaptation is the process of moving from one state of integration or equilibxium to another and the means by which this process can take place smoothly and successfully. Facilitators of adaptation will include values, attitudes, programes and incentives that make change acceptable and understandable. Adaptation in most organizations is a political and negotiating process in which the interests of the individual are likely to be subordinated to the interests of the group, and in which the interests of the less powerful groups may be subordinated to the interests of the more powerful.

\section{Integration}

Integration is the action taken, once goals have been attained, to restore a situation to a state of equilibrium. This involves bringing the different components of tasks, technology, people and structure together into a viable and reasonably stable relationship. Successful integration implies a positive relationship between the new tasks which are a product of the new technology and the needs of the employees who have to perform these tasks.

\section{Pattern maintenance}

Once a new system has been introduced, the essential function of pattern maintenance is to maintain its stability by making it acceptable to the values and norms of the groups associated with it. This requires that users view the system positively and have confidence in its ability to provide the kind of enviromment they need to achieve job satisfaction.

Values and Change in Six Organizations

The six organizations in this research all had different approaches to the 
introduction of computer systems. Three of them, one of the government departments, one industrial firm and the international bank set precise human goals related to job satisfaction at the start of the design process. Two of these, the firm and the bank, used a participative approach in which clerks played a major role in the development of a new form of work organization into which the computer system would be embedded.

The diagram below shows the strength and nature of values in each organization. It can be seen that those organizations which set job satisfaction goals have more ' $Y$ ' oriented managers and systems designers than those which set business or technical goals only. The values of managers and systems designers are also stronger than those of the clerks.

\section{The strength and extent of values in each organization}
$x$ indicates a preference for tightly structured and controlled forms of organization
$Y$ indicates a preference for flexible, self managing forms of organization
$C$ indicates a neutral attitude

Organizations with business and technical goals only.
Organizations with job satisfaction goals.

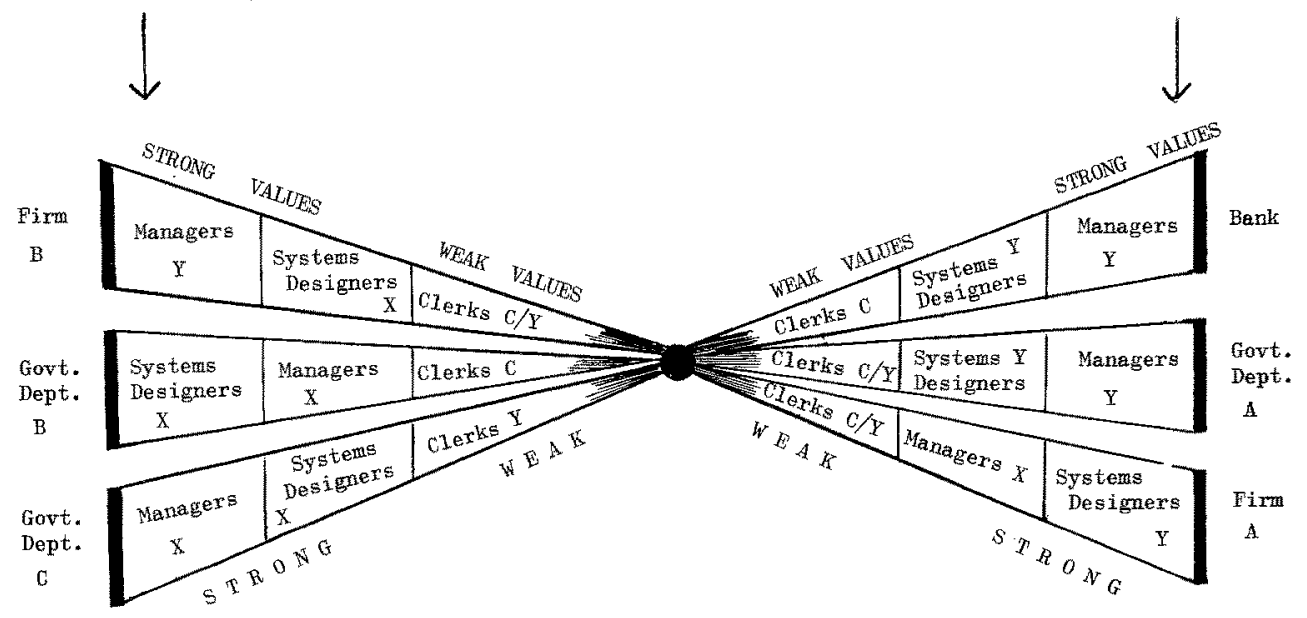

The best value fits are in

a) Government Dept.A

b) Tnternational Bank

The worst are in

a) Govermment Dept. C 
It was hypothesised that a good fit between the values of all the groups associated with a major change would lead to change consequences which are approved of. The data supported this.

\section{The Value Fit}

Organizations which did

not set job satisfaction goals

\section{Government Department C}

Poor fit on values between the clerks and management/systems designers.

Government Department B

Poor fit on values between the clerks and management/systems designers.

\section{Firm B}

Good fit on values between the clexks and management. Less good fit between these two groups and the systems designers.

Organizations which set job satisfaction goals

\section{Government Department A}

Good fit on values between all three groups.

\section{Firm A}

Good fit on values between clexks and systems designers. Less good fit between these two groups and management.

Bank

Good fit on values between clexks and managers and systems designers responsible for design of on-line system.

\section{System consequences}

Computer seen as routinizing work.

Computer seen as disadvantageous in busy offices.

Computer liked in one department, disliked in another.
Computer system approved of. System designed to improve job satisfaction.

Computer system approved of. Initiative to associate new system with new form of work organization came from systems designers.

Computer system approved of. Initiative to associate new system with new form of work organizations came from management and systems designer.

Goal attaimment

Change provides an opportunity for making choices and the kinds of choices that are made provide an insight into the values of the different groups involved in the change process. For example, values may lead to problems being defined in 
such a way that choice opportunities are limited, or conflicts of values and interests may give the choice process a dynamic which makes outcomes difficult to predict.

But values will not be the only influence on the kinds of goals that are set, these will also be constrained by the nature of the decision making environment. This will include the number and diversity of the groups involved, the efficiency of information systems in providing the decision group with relevant, broad based, and up to date information, and the extent to which internal and extermal organizational environments are subject to change. (4)

All the six organizations in this research claimed to have set very precise goals at the start of their projects. The majority of these goals were directed at the attainment of economic, rational or technical objectives. The intellectual model used to attain goals was close to that recommended by Steiner.

Planning is a process that begins with objectives; defines strategies, policies and detailed plans to achieve them; which establishes an organization to implement decisions and includes a review of performance and feedback to introduce a new planning cycle. (5)

This was particularly true of the government departments whose extremely large systems involved the setting up of a network of groups to take and implement decisions. The formulation of clear objectives appeared to give a sense of order, clarity and purpose to the design process although it may have had the disadvantage of inhibiting the exploration of alternative futures once the movement towards goals had begun. $(6)$

Listed on the next page are the principal goals set by the six organizations, the environmental influence that stimulated the goal and an assessment of whether the goal was successfully achieved. All of these goals, with the exception of the economic goal that the system must pay for itself, were a response to some perceived discrepancy between the existing situation and the situation as an influential group in the organization would like it to be. (7) This discrepancy acted as a stimulus for change. An interesting feature of the goal setting process was that technical goals did not dominate. Sackman has described very critically how the programers and systems analysts of the fifties and sixties were technically blinkered. He says,

Most programers tended to view accommodation for users as costly and disconcerting in the more urgent business of building programs and making them work with limited resources. (8)

In contrast to this technical perspective, the strongest influence in the six 


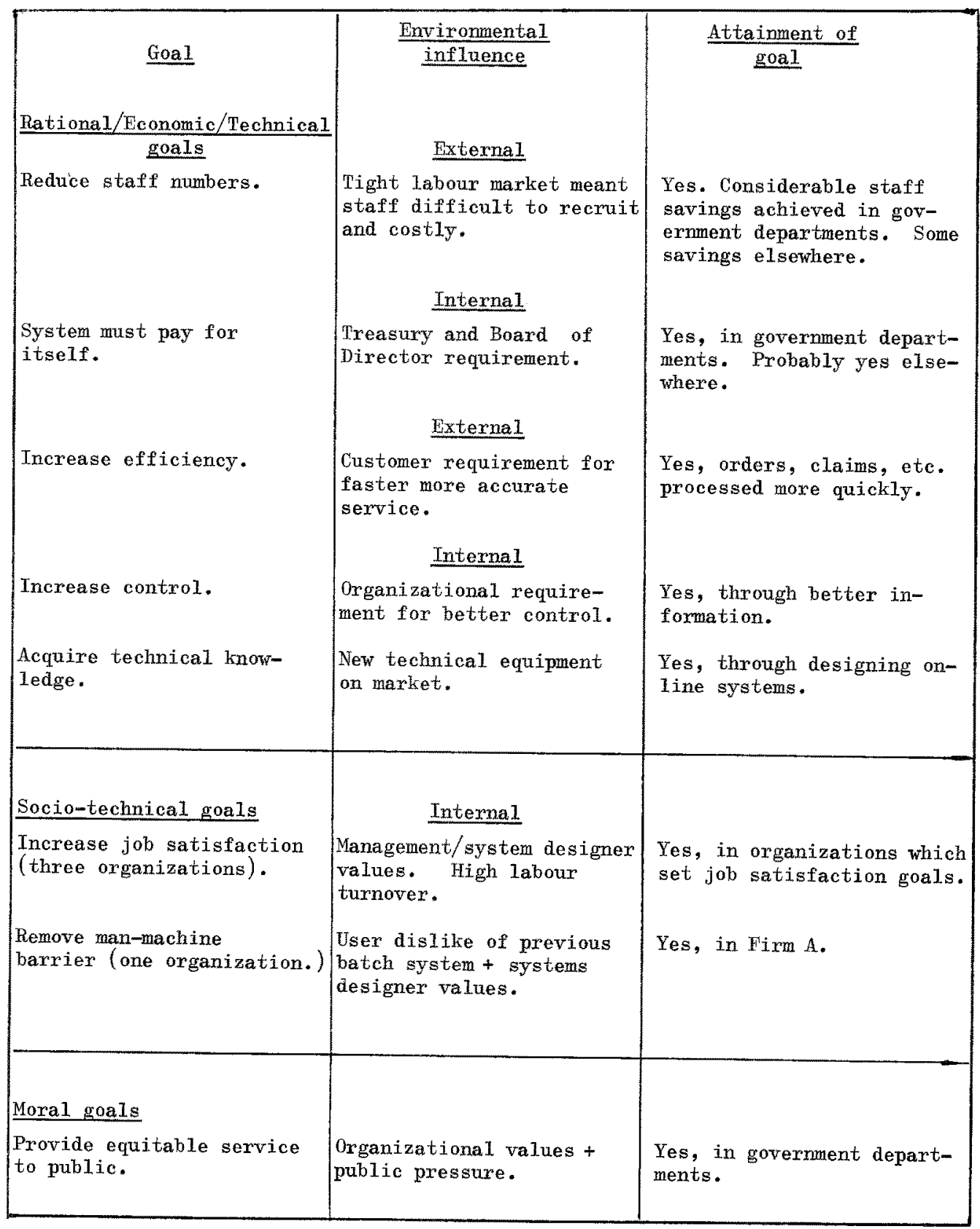

organizations was the wish to achieve what were seen as important business requirements; the reduction of costs and the impxovement of efficiency. In those organizations which set social or soeio-technical goals, the needs of user management and clerks were given high priority, although not at the expense of efficiency. This business and social orientation was a consequence of a number of factors. 
First, computer systems are easier to design today and therefore technical constraints are fewer. Second, the power situation has altered as a result of a wider spread of knowledge through increased use of computers. Effectively computer specialists have lost their monopoly of EDP information. In the government departments the systems designers were recruited from staff who had previously worked as administrators in the areas which were computerised, and therefore had considerable knowledge of and sympathy for the needs of the user, at least at managerial level. The two firms and the bank were introducing their second stage of computerisation and the systems designers were all conscious that their design responsibility covered the setting and meeting of business as well as technical goals. They therefore worked in close association with user management throughout the design process.

Another feature of the goal attainment process was that the goals were all attainable, and all attained, suggesting perhaps that innovators who are going to be later judged on the success of their actions do not make explicit objectives which are difficult, uncertain, and may not be achieved. The principal features of the goal attainment process can be summarized as follows.

1. Goals did reflect organizational values and were associated with the attainment of business and human rather than technical objectives.

2. A number of important goals represented the values of organizational sub-groups. For example, the sociotechnical goals related to increasing job satisfaction originated with management in government department $B$ and in the bank, and with the systems designers in Firm A.

3. Those who participated directly in the early stages of the systems design process, for example, user management, were able to influence the nature of the goals set.

4. The goals that were formally set and made explicit were those that could be attained without difficulty. This enabled the systems to be seen as a 'success' when they were. evaluated after implementation.

The choices associated with the design of the social part of the systems are of particular interest. In the three oxganizations which did not set any positive human goals for their own staff, government departments $B$ and $C$ and Firm $B$, the reasons given for not doing so were as follows.

1) Job satisfaction was not seen as the responsibility of the systems design team. It was perceived as the responsibility of the user manager or the local office. 
2) In the government departments human goals were related to the needs of the public, not the needs of staff.

3) The participation of user management in systems design led to priority being given to managerial goals such as efficiency and security. There was a belief that greater work flexibility could threaten the attainment of these.

4) Systems designers saw clerís as compliant and unlikely to protest.

5) Clerks were viewed primarily as resources facilitating the operation of an administrative system.

In each of the three organizations which set specific human goals great thought was given to different ways of organizing work and to the creation of interesting and challenging jobs. In goverument department $A$ this was done entirely by the systems designers and management. In Firm A design alternatives were worked out by the systems designers assisted by the author and with considerable consultation with the clerks. The knowledge acquired by the elerks during this process led to them rejecting the job enrichment solution recommended by the systems designers and substituting their own, based on the creation of autonomous groups. In the bank, total responsibility for the design of the social system was given to a representative group of user clerks who also chose an autonomous group form of organization.

The fact that social as well as technical goals had been set had two consequences for the systems designers. First, it made the systers design process more complex, requiring a knowledge of social as well as technical systems design. Second, it introduced the constraint that technical design had to be very flexible so that the technical part of the system did not inhibit any desired social solution. Three conclusions can be drawn from an examination of the consideration given to human design alternatives. These are that, in the six organizations,

1) If a human goal such as an increase in job satisfaction was accepted and made explicit then considerable efforts would be made to attain it.

2) If no precise human goals were set then little attention would be paid to human needs in the systems design process.

3) If the user, particularly the user clerk, participated in or controlled the design of the social system then goals which were important to users, such as job satisfaction, were likely to be attained.

\section{Adaptation}

Any major change process is a test of an organization's philosophy. It will 
show whether the philosophy has adequately prepared the organization for change, and if it assists the successful management of change. The organization has to be capable of introducing and legitimizing new objectives, procedures and attitudes and of creating a structure and a set of levers to enable it to do this. It requires what Gross has called an 'institutionalized capacity to build other institutions' which in turn requires 'the development and maintenance of a network of supporting groups'(9). Edstrom has suggested that when large-scale computer systems are being designed there will be a great deal of top management intervention for this group will wish to influence the outcome of a change that is going to have considerable organizational impact. (10)

The structures set up to assist adaptation in our six organizations are shown below. It can be seen that Edstrom's hypothesis is supported, for the three government departments had senior management steering comittees whose role was the formulation of policy and the evaluation of proposals from the systems design groups.

\section{Adaptation Structures}

Adaptation structure

Government departments

Steering Committee.

Liais on Comittee.

User Committees.

Design groups with user members.

Implementation ox Conversion Cormittees or teams.

Consultative

(Whitley Committee).
Organizational

level of

membership

Senior management.

Seniox systems

designers, Users, Trade Union, Board.

Management.

EDP, Management.

Management, Special Group.

clerks.

Systems designers, User management, Personnel department, Trade Union.
Adaptation function

Change policy.

Change policy.

Development of new procedures.

System transformation.

System transformation.

Problem identification once system was implemented.

Change policy and progress. 


$\begin{array}{lll}\text { Adaptation } & \frac{\text { Organizational }}{\text { Ievel of }} & \text { Adaptation } \\ \text { structure } & \text { membership } & \text { function }\end{array}$

Industry and Bank

\begin{tabular}{|c|c|c|}
\hline Progress Committee. & EDP, Management & $\begin{array}{l}\text { Decide priorities, } \\
\text { monitor progress. }\end{array}$ \\
\hline User Committee. & $\begin{array}{l}\text { BDP, Management } \\
\text { Clerks. }\end{array}$ & $\begin{array}{l}\text { Development of new } \\
\text { procedures. }\end{array}$ \\
\hline $\begin{array}{l}\text { Job satisfaction } \\
\text { working parties. }\end{array}$ & Clerks. & $\begin{array}{l}\text { Design of work } \\
\text { organization. }\end{array}$ \\
\hline $\begin{array}{l}\text { Implementation } \\
\text { working parties. }\end{array}$ & Clerks. & $\begin{array}{l}\text { System transform- } \\
\text { ation. }\end{array}$ \\
\hline
\end{tabular}

Each organization was careful to involve its user management in all aspects of the change process. In government department $\mathrm{C}$, and to a lesser extent in government department $A$, management itself formed the design team and so adaptation came as a result of direct participation in system development. Government department $B^{\prime} s$ system was designed by a centralized systems group and care had to be taken to ensure that the user's view was represented through the cooption of users onto this team. In the firms and the bank every effort was made to design the kind of system that management wanted and this policy stimulated managerial enthusiasm for the change. Managerial participation was formalized through the setting up of user committees with responsibility for developing new administrative procedures to fit the new level of technology. These efforts to involve management were in sharp contrast with the situation ten years ago when the author was studying the introduction of computer systems in other organizations. A common policy then was for the EDP group to design a system and 'selI' it to management. It was believed at that time that management's ignorance of computers meant that it had nothing to contribute to systems design. But, whereas participation at management level was considerable, this was not true at the level of the clerks, except in those organizations which set job satisfaction goals.

The creation of a support network of comittees did appear to assist adaptation in the six organizations. These committees provided opportunities for influence, for negotiation, for learning, and for taking responsibility. They worked best when the members were not restricted to a passive role of question or coment but were given specific tasks so that they could actively contribute to policy or design. Each organization formed groups of this kind at management level. Two of the organizations which set job satisfaction goals also created representative groups of clerks.

There are many strategies which one group can use to ensure the compliance 
or cooperation of another. There is compliance through deference, because a group knows its place; or through trust because there is confidence that the right thing will be done. There is compliance through the understanding which comes from good communication. There is compliance through negotiation and through shared control and participation in decisions. Which of these strategies is used will be determined by power, by expediency and by values. The chart below shows the strategies used in the six organizations.

Adaptation Strategies

$\frac{\text { Communication }}{\underline{\text { with }}} \frac{\text { Consultation }}{\underline{\text { with }}} \quad \frac{\text { Participation }}{\underline{\text { indecisions }}} \frac{\text { Control }}{\underline{\text { by }}}$

Govermment

Departments

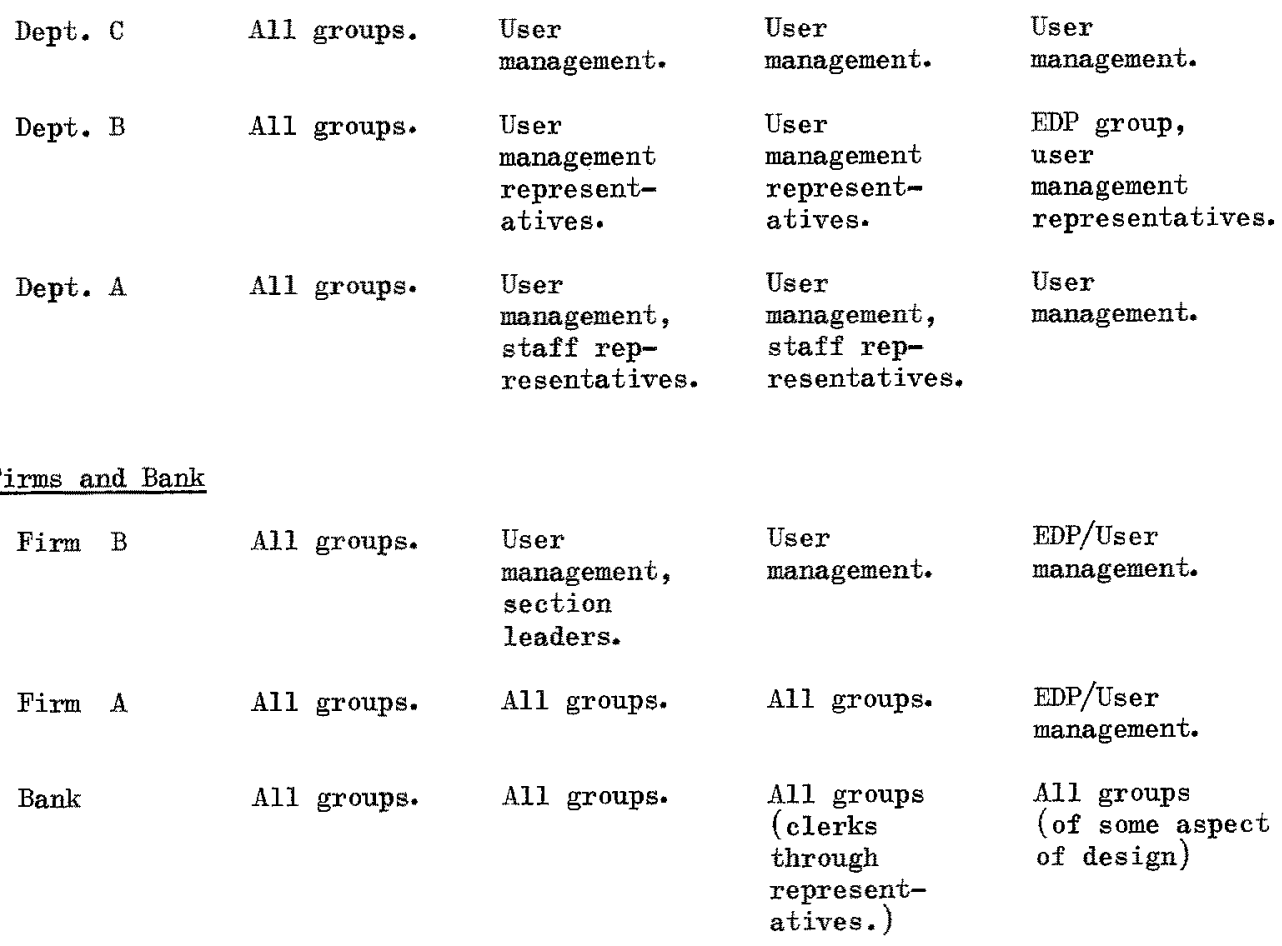

There are four arguments for involving lower level groups such as clerks in a more fundamental way than mexely communicating to them what is going to happen. The first is a values argument which states that people have a moral right to control their own destinies and that this applies as much in the work situation as elsewhere. (11) The second is an expediency argument and states that activities are ultimately controlled by those who perform them, and that people who do not have a say in decisions may decide to repeal the decisions of others as soon as 
those others leave the scene. (12) The third relates to the location of knowledge and states that the experts on operational factors such as task design are the people who do these jobs. (13) The fourth argument is that involvement acts as a motivator. (14) Firm A and the bank were probably most influenced by the third argument, with the first also carrying some weight; government department $A$ by the first and fourth arguments.

An important function of adaptation structures and strategies is to reduce the ambiguity and equivocality in the change process and to give people a sense of control, knowledge and purpose; an understanding of where they are going and what they are trying to achieve. The six organizations created a comprehensive network of groups to assist adaptation, whose roles varied from the creation of policy to responsibility for specific tasks.

\section{Integration}

Adaptation has been defined as the movement from one integrated set of relationships to another. Integration is when a number of parts of a system are mutually adapted to each other and contributing to the successful functioning of the system as a whole. These parts or units can be people or things or a combination of the two as in the concept of a sociomtechnical system. Integration is made difficult by the fact that organizations are complex entities that function on several levels and contain groups whose different interests are often in conflict. (15) Some writers have argued that integration was only possible when employees did not question the logic of the bureaucratic organizations in which they worked whereas today, not only are organizations rational, rational habits of mind have also infected the work force and they are now questioning what they previously accepted. (16) others believe that integration has never been possible; that there are no social systems that can be perfectly integrated with their cultural systems and with the personality systems of their members, that the values institutionalized in a social system will always be somewhat inappropriate to some paxts of that social system. It has also been argued that too tight an integration is not even desirable as it removes the stimulus for change. (17)

When technical change has been introduced, successful integration requires the bringing together of people, tecmology and structure into a viable and stable relationship. (18) This has to be done within the context of an organization with values and goals as shown in the diagram on the next page. The relationship between these four variables needs to be stable but it should not be static. 0rganizations should be able to respond to new pressures from their enviroments while at the same time maintaining a state of equilibrium ox being able to make adjust- 


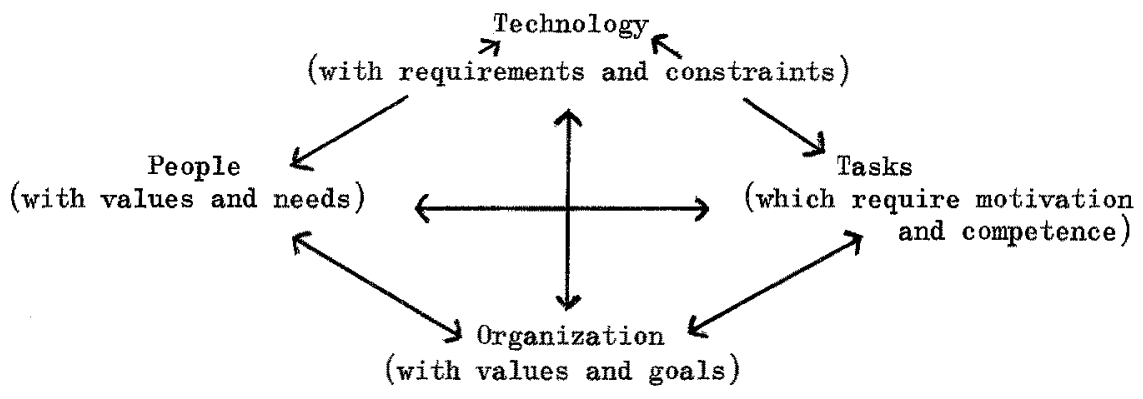

ments which restore equilibrium if internal relationships are badly disturbed. The introduction of a new computer system is likely to affect each of the variables in the diagram. A new level of technology will bring with it a new man-machine relationship incorporating both opportunities and constraints. Because tasks are altered by technology, the task structure of departments using the computer will be affected. New tasks mean that new demands will be made of people and this will affect job satisfaction positively or negatively depending upon whether the new situation meets their values of what is desirable work. In turn, the technology, tasks and people variables will interact with an internal organizational enviroment which provides a structural context for the achievement of the organization's purpose, and this interaction may start the looping process again by making new demands of technology. A lack of recognition of the importance of integrating these variables when introducing computer systems is seen as an important source of their failure.

In this research the author concentrated on examining two aspects of integration. The first was the extent to which technology and tasks were brought together into a set of interesting and stimulating activities which met the criteria associated with good job design. The second was how well this combination of technology and tasks was integrated with the values and needs of employees and produced feelings of job satisfaction.

\section{Technology, values, and task structure}

There is now considerable evidence that most employees prefer jobs that provide an opportunity for the use of discretion, meaning by this using judgement, making choices, taking decisions. The exercise of discretion gives them a feeling of personal identity and responsibility which contrasts with routine work which can induce a sense of worthlessness ox anonymity. One way of providing discretion. is through organizing employees into multi-skilled, self managing groups with responsibility for handling an important set of activities. Such groups are often called 'autonomous'. 
The three organizations, which set job satisfaction goals all created autonomous group structure for their staff; and these ensured opportunities for the use of considerable discretion, together with responsibility for meeting the needs of a specific group of customers or clients. If our hypothesised relationship between values and action is correct then the values of the managers and systems designers in these three organizations ought to support this kind of work structure and we have evidence that this was the case.

The values of the managers and systems designers in the organizations which set job satisfaction goals compared with the values of those in the organizations which did not set such goals.

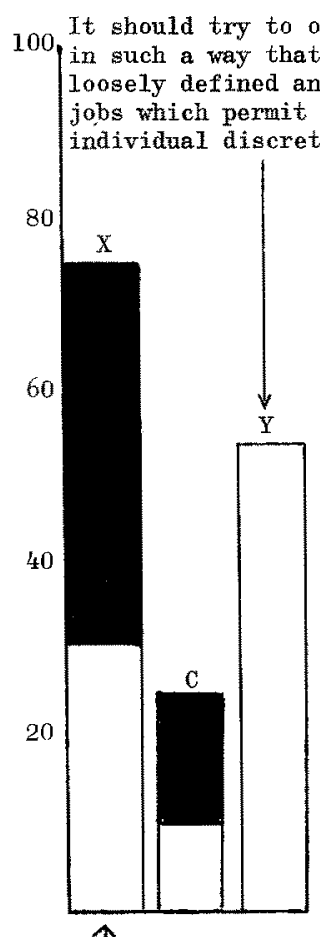

$\uparrow$

It should try to organise work activities into tightly structured jobs which are clearly defined and do not permit a great deal of individual discretion

Organizations with job satisfaction goals.

$N=13$ managers/systems designers

Organizations without job satisfaction goals

$N=11$ managers/systems designers

X

The development of job methods should be left to the group and individual doing the job

Jobs should be flexible and permit group problem solving

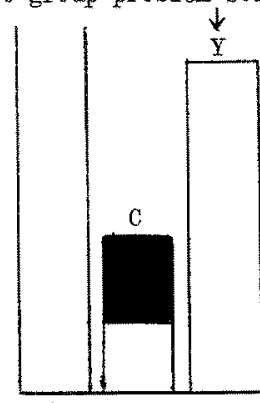

$\uparrow$

Jobs should be clearly defined, structured and stable

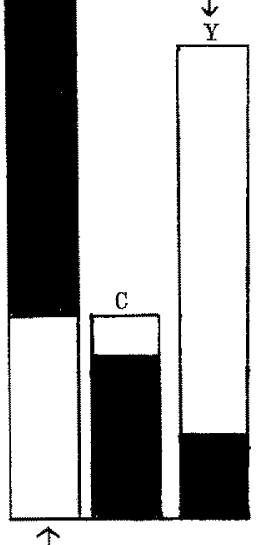

Jobs should be carefully defined by 0 \& $\mathrm{M}$ department, management services or supervision and adhered to 
It can be seen that no managers and systems designers in organizations which did not set job satisfaction goals are on the $X$ part of the scale on the left and centre charts, and only $9 \%$ on the right hand chaxt. In contrast a majority of managers and systems designers in the organizations which did set job satisfaction goals are on the $Y$ side on two of the three questions. In the oxganizations which did not make job satisfaction a system objective no effort was made to remove routine work through associating new wox structures with the new computer system; and in one of them the computer led to a considerable increase in routine.

Fox has pointed out that what is being discussed here is the degree of confidence and trust between management and subordinates. Routine jobs with low discretion imply that the manager believes that his subordinates cannot be trusted, of their own volition, to perform according to the organization's goals and values. He also points out that trust is a reciprocal relationship. A management that does not trust its employees will not be trusted by them. (19) computer systems therefore require that careful thought is given to developing the kind of relationship between technology and work organization that provides staff with discretion and control; but this will only happen if management and systems designers have personal values which are humanistic.

\section{Pattern Maintenance}

Pattern maintenance requires the continuance of a state of integration once this has been achieved after a major change. Every social system is governed by a value system wich specifies the nature of the system, its goals, and the means for attaining these goals and equilibrium is achieved when values and goals enable the system to cope effectively with its environment. Integration and equilibrium require that individuals are socialized and educated in a society's values and that conflict resolving mechanisms exist for resolving major disagreement on values. (20) This presents us with today's dilemma and challenge for the aspects of change that have been discussed in this papex - goal attaimment, adaptation, integration and pattern maintenance a11 require that the members of a society be more or less comitted to a set of values and goals and agree on how they shall be achieved. The problem fox the future is surely that of being able to hold societies together without violent insurrection or civil war, while at the same time assimilating and controlling new ideas which lead to changes in values. Some commentators see us as now entering what has been called the post-industrial era in which new needs and values will lead to new organizational structures and designs for jobs. Cultural values will change from an emphasis on achievement, self-control, independence and endurance of distress to self actualization, self-expression, interdependence and a capacity for joy. (21) 


\section{Conclusions}

The evidence from this study shows that in the six organizations that were investigated, values did influence the objectives, design and assimilation of computer systems. In three organizations the values of the groups responsible for systems design did not include the humanization of work. Because different values were given priority, the oppoxtunity to associate a new technology with a new and more satisfying form of work organization was not taken advantage of. The unsatisfactory results of this policy showed up most clearly in government department $\mathrm{C}$ where greater routinization of work contributed to the low job satisfaction of intelligent young clerks.

In the organizations which set job satisfaction goals, in contrast, the introduction of a new level of technology was recognized as an opportunity to increase job satisfaction and this was done for humanistic as well as practical reasons. These organizations not only made job satisfaction a systems objective, they gave the clerks themselves a major role in the design of the new work organization which would be associated with the new computer system.

Schon believes that there are two powerful pressures in society today, these are the call to Return and the call to Revolt. The first tells us to return to the old ways and standards, to try and retrieve the vanished stability. The call to Revolt says that there is increasing alienation in society and that we must develop new values and objectives. (22) The practical problem for those who, like the author, believe that technology can be an instrument for human well being mather than a threat to this, is how to assist the development of these new values.

There are many suggestions on how a change of values is and can be made. Kuhn has put forward the scientific 'crisis' theory, which suggests that when existing paradigms cease to solve problems, they will be replaced with new ones. (23) The strategy here would be to draw attention to this kind of failure. Parsons believes that a system's inherent tendency to adjust when discrepancies occur between its needs and the external enviromment will keep it in a state of stability, providing there is value consensus on what these needs are. (24) This suggests that an emphasis should be placed on the development of shared values of a kind different Irom those of the past. Hedberg maintains that an increasing awareness of change consequences can be achieved through making values explicit. (25) Fox's view is that low trust relationships between management and employees should be replaced by high trust relationships, and that providing employees with opportunities for the use of discretion is a manifestation of this trust. (26) 
Al1 of these diagnoses and suggestions axe insightful and helpful and will be increasingly debated in the future. In this paper the emphasis has been on the role of computers as a vehicle for change and the author's belief is that this technology can be used as an agent for 'technological bonding' so that it contributes to an enhancement of the quality of working life. Computers and automation can be an agent for good or bad, our values will detexmine what we regard as good or bad.

\section{References}

1. Parsons, T. and Shils, E.

2. Menzies, K.

3. NeaI, M.A.

4. Friedmann, $J$.

5. Steiner, G.

6. McCaskey, M.B.

7. Vickers, G.

8. Sackman, H.

9. Gross, I.

10. Edstrom, A, and Nanges, $I$.

11. Mumford, E.

12. Hedberg, $B$. Nystrom, P. and Starbuck, W.

13. Edstrom, A.

14. White, J.K. and Ruh, R.A.
(1951) Towards a General Theory of Action; Harvard Tniversity Press.

(1976) Talcott Parsons and the Social Image of Man, London: Routledge and Kegan Paul.

(1965) Values and Interests in Social Change. Englewood Cliffs, N.J.: Prentice Hall.

(1967) "A conceptual model for the analysis of planning behaviour", Administrative Science Quarterly. Vol.12 (2) $225-252$.

(1969) Top Management Planning, New York: Macmillan.

(1974) 'A contingency approach to planning: planning with goals and without goals '. Academy of Management Journal. Vol.17 (2) 281-289.

(1973) Making Institutions Work, London: Associated Business Programes.

(1971) Mass Information Utilities and Social Excellence, New York: Aurbach.

(1967) Sociological theory: Inquiries and Paradigms: New York: Harper and Row.

(1974) The implementation of computer based information systems under varying structural conditions" . Paper presented to Altorg Conference, Gothenburg.

(1978) The design of work: new approaches and new needs ${ }^{t}$. Paper presented at TFAC Conference, Enschede, Holland, 1977.

(1976) 'Camping on Seesaws: prescriptions for a selfdesigning organization', Administrative Science Quarterly. Vol.21 (1) 41-62.

(1974) Op. Cit.

(1973) The effects of personal values on the relationship between participation and job attitudes'. Administrative Science Quarterly. Vol.18 (4) $506-514$. 
15. Touraine, A.

16. Fitzgerald, T.H.

17. Gowler, D. and Legge, $\mathrm{K}$.

18. Leavitt, H.

19. Fox, A.

20. SmeIser, N.

21. Davis, L.E.

22. Schon, D.A.

23. Kuhn, T.S.

24. Parsons, T.

25. Hedberg, B.

26. Fox, A.
(1974) The Post-Industrial Society, London: Wildwood House.

(1971) 'Why motivation theory doesn't work' . Harvard Business Review. July-August.

(1972) 'Occupational role development, part one'. Personne1 Review. Vol.1. (2) 12-27.

(1958) Managerial Psychology, University of Chicago Press.

(1974) Beyond Contract:Work, Power and Trust Relations. London: Faber.

(1959) Social Change in the Industrial Revolution. London: Routledge and Kegan Paul.

(1971) Job satisfaction research: the post-industrial view", Industrial Relations, Vo1.10. 176-193.

(1967) Technology and Change. London: Pergamon Press.

(1962) The Structure of Scientific Revolutions, The University of Chicago Press.

(1964) The Social System. New York: Eree Press.

(1975) Computer systems to support industrial democracy' in E. Mumford and H. Sackman (Eds,) Human Choice and Computers. Amsterdam: North Iolland.

(1974) Op*Cit. 